\title{
Genetic analysis of calf survival at different preweaning ages in beef cattle
}

\author{
F. Goyache ${ }^{\mathrm{a}, *}$, J.P. Gutiérrez ${ }^{\mathrm{b}}$, I. Alvarez ${ }^{\mathrm{a}}$, I. Fernández ${ }^{\mathrm{a}}$, L.J. Royo ${ }^{\mathrm{a}}$, E. Gómez $^{\mathrm{a}}$ \\ ${ }^{a}$ SERIDA-CENSYRA-Somió, C/Camino de los Claveles 604, E-33203 Gijón, Asturias, Spain \\ ${ }^{\mathrm{b}}$ Dpto. de Producción Animal, Facultad de Veterinaria, Universidad Complutense, E-28040 Madrid, Spain
}

Received 1 August 2002; received in revised form 21 January 2003; accepted 11 February 2003

\begin{abstract}
The aim of this paper is to assess the suitability of including calf survival traits in the breeding objective of beef cattle improvement programs. To do so, we analysed the genetic parameters affecting calf survival during the perinatal period (PS), between the perinatal period and weaning (LM) and at weaning (WS) using Asturiana de los Valles breed field data. Up to 36125 calf survival records were used in the analysis. Heritabilities estimated for the direct effect ranged from 0.033 to 0.084 for PS, from 0.011 to 0.112 for LM and from 0.039 to 0.142 for WS. Our results suggest that LM is not affected by a maternal genetic component, whereas its effect is slight and similar in magnitude for both PS and WS. In general, the analysed traits are affected by a slight maternal permanent environmental effect ranging from 1 to $2 \%$. PS and WS seem to be consistently determined by the same genes, presenting genetic correlations between the respective direct or maternal genetic effects of 0.95 and 1.0. Genetic correlation between the direct effects affecting PS and LM was 0.745. Current analyses show that WS has a higher genetic variability than would justify the inclusion of calf survival at weaning in the beef cattle breeding objective.
\end{abstract}

(C) 2003 Elsevier B.V. All rights reserved.

Keywords: Beef cattle; Genetic correlation; Heritability; Calf losses; Breeding objective; Asturiana de los Valles

\section{Introduction}

Improvement in cattle has traditionally focused on productive traits. However, modern cattle breeding programmes should consider all the traits of economic importance in order to optimise total genetic gain. In beef cattle, whatever the production system, breeding traits appear to be the most economically

\footnotetext{
*Corresponding author. Tel.: +34-985-195-303; fax: + 34-985195-310.

E-mail address: fgoyache@serida.org (F. Goyache).
}

important traits (Newman et al., 1992) and only a dramatic decrease in the market price of beef would affect the relative weighting of reproductive traits in relation to growth and carcass traits (Phocas et al., 1998). The mortality of calves from birth to weaning reduces beef farm incomes and adds significantly to beef production costs (Philipsson, 1976e; Wittum et al., 1993). It is thus necessary to integrate calf survival traits in the definition of an overall breeding objective in beef cattle.

Calf survival at a given age has normally been studied as a dichotomous variable, mainly at perinat- 
al stage (Philipsson, 1976a,b,c; Meijering, 1984) and especially in dairy cattle (Weller et al., 1988; Weller and Gianola, 1989; Meyer et al., 2000, 2001). Perinatal survival has been characterised as having low heritability (Cubas et al., 1989; Philipsson, 1976c) and available estimates of heritabilities are low for both direct and maternal components. However, most reported heritabilities in beef cattle are at least 2-fold those found in dairy cattle (Koots et al., 1994a). This would suggest the possibility of using this higher genetic variability for calf survival in beef cattle improvement programs.

Despite its economic importance for suckling cow production systems, phenotypic and genetic studies on calf survival at weaning are scarce and little information is available (Cundiff et al., 1986; Ray et al., 1989). Late mortality, occurring from the perinatal period to weaning, is usually considered to be mainly affected by environmental factors such as sporadic diseases or accidental losses (Cubas et al., 1989; Ray et al., 1989). Consequently, studies on late preweaning mortality and survival at weaning of the calf are scarce and the possible genetic basis affecting the ability of the calf to be born alive and survive different periods till weaning have not yet been ascertained.

We have estimated genetic parameters for productive, reproductive and type traits in the Asturiana de los Valles beef cattle breed (Gutiérrez et al., 1997, 2002; Goyache and Gutiérrez, 2001; Goyache et al., 2002; Gutiérrez and Goyache, 2002). Our interest is to ascertain the genetic basis affecting traits that have been shown to be important so as to include these in the breeding objective (Phocas et al., 1998). The aim of this paper is to estimate the genetic relationships between calf survival traits at different ages in order to evaluate the possibility of including this information in beef cattle improvement programs. This aim has focused basically on: (a) ascertaining the genetic relationships between survival of calves at weaning and earlier survival traits, and (b) determining the importance of the maternal influence on calf survival.

\section{Materials and methods}

Field data of calf losses and pedigree information of the Asturiana de los Valles breed were obtained from the performance recording database (the CORECA database) implemented by the Regional Government of the Principado de Asturias (Northern Spain), through the Asturiana de los Valles Breeders Association (ASEAVA). Performance recording had been implemented based on nuclei, grouping farms according to their proximity and their production system, resulting from the small size of farms (Gutiérrez et al., 1997; Goyache and Gutiérrez, 2001). Calf losses were recorded in the CORECA database using the definitions listed in the BIF Guidelines (1986) with the following scores: 1 (calf alive at weaning), 2 (calf sold before weaning), 3 (calf alive at $72 \mathrm{~h}$ but dead before weaning), 4 (calf alive at birth but dead within $72 \mathrm{~h}$ ) and 5 (calf dead at birth). Throughout this paper the ability of a calf to survive at different ages was defined as follows:

(a) Perinatal survival of calf (PS): a dichotomous variable combining the aforementioned calf loss scores 4 and 5 as 1 and the other scores as 2. PS is expected to characterise the ability of a calf to be born alive and survive $72 \mathrm{~h}$.

(b) Late mortality of calf (LM): a dichotomous variable considering calf loss score 3 as 1 and scores 1 and 2 as 2 . LM is expected to characterise the inability of the calves surviving the perinatal period to survive till weaning, whatever the cause of death.

(c) Weaning survival (WS): a dichotomous variable considering calf loss scores 3,4 and 5 as 1 and scores 1 and 2 as 2 . WS is expected to characterise the ability of the calves born alive to be alive at weaning.

Only single calving records including calf loss score, sex of calf and calving number of the dam were considered. Animals with identification errors or ambiguous birth dates were eliminated. The comparison group was defined as nucleus-year of calving. Comparison groups including less than 10 records were eliminated. Thirty percent of the comparison groups included less than 40 records and $55 \%$ included less than 80 records. Only $10 \%$ of the comparison groups included more than 200 records. Eventually, the analysed database included 36125 records (34 374 for LM). Distribution of available records by age of dam and sex of calf is shown in Table 1. Artificial insemination is widely used in the 
Table 1

Distribution of total available records, early calf losses (calves born dead or dead within $72 \mathrm{~h}$ ) and late calf losses (calves alive after $72 \mathrm{~h}$ but dead before weaning) in absolute and relative (in percentages) frequencies by age of dam and sex of calf

\begin{tabular}{|c|c|c|c|c|c|}
\hline & \multirow{2}{*}{$\begin{array}{l}\text { Total } \\
\text { no. }\end{array}$} & \multicolumn{2}{|c|}{ Early losses } & \multicolumn{2}{|c|}{ Late losses } \\
\hline & & $n$ & $\%$ & $n$ & $\%$ \\
\hline \multicolumn{6}{|c|}{ Two-year-old: } \\
\hline Male & 1563 & 160 & 10.24 & 73 & 4.67 \\
\hline Female & 1525 & 123 & 8.07 & 69 & 4.52 \\
\hline \multicolumn{6}{|c|}{ Three-year-old: } \\
\hline Male & 2286 & 181 & 7.92 & 107 & 4.68 \\
\hline Female & 2218 & 129 & 5.82 & 84 & 3.79 \\
\hline \multicolumn{6}{|c|}{ Four-year-old: } \\
\hline Male & 2407 & 150 & 6.23 & 103 & 4.28 \\
\hline Female & 2453 & 93 & 3.79 & 80 & 3.26 \\
\hline \multicolumn{6}{|c|}{ From 5-to 10-year-old: } \\
\hline Male & 10189 & 458 & 4.50 & 388 & 3.81 \\
\hline Female & 9291 & 301 & 3.24 & 289 & 3.11 \\
\hline \multicolumn{6}{|c|}{ Older than 10 years: } \\
\hline Male & 2210 & 100 & 4.52 & 87 & 3.94 \\
\hline Female & 1993 & 66 & 3.31 & 64 & 3.21 \\
\hline Total & 36135 & 1761 & 4.87 & 1344 & 3.72 \\
\hline Male & 18655 & 1049 & 5.62 & 758 & 4.06 \\
\hline Female & 17480 & 712 & 4.07 & 586 & 3.35 \\
\hline
\end{tabular}

Asturiana de los Valles breed (Gutiérrez et al., 1997, 2002), generating close genetic connections between herds. Our database included 1797 sires for PS and WS and 1750 for LM. A total of 1281 sires had progeny in the data for PS and WS (1245 for LM). The average number of progeny records per sire was 26.35 for PS and WS and 25.84 for LM. Pedigree information included 15,437 additional animals (14 970 for LM). Thus, 51562 animals (49 344 for LM) were involved in the estimations of the genetic parameters. The number of dams that have themselves observed as calves were 2818 for PS and WS (2645 for LM). So, our database can be useful to estimate reasonably the covariances between direct and maternal genetic effects for the analysed traits.

The three traits defined above were modelled as continuous traits and assumed to be sampled from a multivariate normal distribution (Meyer et al., 2001). Since the estimates of genetic parameters in dichotomous traits may depend on the population mean for the trait, threshold models would better account for the probabilistic structure of categorical data than linear models do. Heritabilities estimated using threshold models are much larger than those derived from linear models (Meijering, 1984; Weller et al., 1988;
Weller and Gianola, 1989). However, when the amount of information for fixed effects is small, as in the present study, threshold models have problems in estimating variance components and may prove unreliable (Altarriba et al., 1998). Moreover, Matos et al. (1997), according with several other previous studies, found that the goodness of fit of linear and threshold models to analyse discrete data was similar, and with respect to prediction ability, differences between linear and threshold mixed models were negligible. These authors conclude that there is little incentive for the use of threshold models over linear models, especially considering the use of threshold models significantly increases the computational effort.

Genetic parameters were estimated via univariate or multivariate REML procedure applied to a mixed linear model. All runs were carried out using the DF-REML program (Meyer, 1989). The fitted model included the following fixed effects: herd-year of calving as comparison group, calving season (two levels: from 1 January to 30 June and from 1 July to 31 December), sex of calf (male or female) and age of dam in days as a linear covariant. As regards random effects, four different models were defined: 
- Model 1: univariate animal model, considering the analysed variables as calf traits, including the additive genetic effect $(u)$, the maternal permanent environment $(c)$ and the residual $(e)$, with the additive genetic effect $(u)$ being the only random effect dependent on the relationship matrix.

- Model 2: like Model 1, but considering the analysed variables as dam traits.

- Model 3: univariate animal model including the additive $(u)$ and maternal $(m)$ genetic effects and the covariance between them $\left(\operatorname{cov}_{u m}\right)$, all three effects being dependent on the relationship matrix, the maternal permanent environment $(c)$ and the residual (e).

- Model 4: bivariate animal model, where PS is analysed with each of the other survival traits, including the direct genetic effect, the maternal genetic effect and the residual as random effects in the model for each trait besides the covariance between either direct $\left(\operatorname{cov}_{u u}\right)$ and maternal $\left(\operatorname{cov}_{m m}\right)$ genetic effects.

Additional information on the maternal genetic component of the analysed variables was obtained by combining information from Model 1 and Model 2. Assuming that $\mathrm{u}$ in Model 2 includes half of the direct effect assignable to the calf and all the maternal genetic effect, we estimated an 'equivalent heritability' of the maternal genetic effect $\left(\operatorname{Eq}\left(m^{2}\right)\right)$ as:

$\operatorname{Eq}\left(m^{2}\right)=\left[4 \operatorname{Var}(u)_{\mathrm{M} 2}-\operatorname{Var}(u)_{\mathrm{M} 1}\right] / \operatorname{Var}(T)_{\mathrm{M} 1}$ where $\operatorname{Var}(u)_{\mathrm{M}}$. denotes the direct genetic variance for the corresponding model and $\operatorname{Var}(T)_{\mathrm{M} 1}$ denotes the total phenotypic variance for Model 1. This $\mathrm{Eq}\left(m^{2}\right)$ is considered to be informative with respect to the existence of a consistent maternal genetic effect affecting calf survival traits.

\section{Results}

Genetic and environmental variances estimated for the different traits analysed using Models 1-3 are presented in Table 2. Estimated heritabilities for the analysed variables are low, regardless of whether they were analysed as calf or dam traits. However, they are at least 2-fold higher for Model 1 than for Model 2. Estimated heritabilities considering the variables as calf traits ranged from 0.057 for LM to 0.106 for WS. When they were considered as dam traits, heritabilities ranged between 0.011 for LM and 0.044 for WS. A slight maternal permanent environmental effect was estimated for all the traits in Model 1 except for LM. In contrast, the highest estimation of $c^{2}$ for Model 2 was for LM (0.10).

Maternal influence on the analysed traits was assessed by combining the information from Model 1 and Model 2. $\mathrm{Eq}\left(\mathrm{m}^{2}\right)$ was low and similar in size for PS and WS (0.012 and 0.016, respectively) but unrealistic for LM. In this sense, LM could be configured as a calf trait whilst actually being a possible maternal influence on the trait of non-genetic origin.

Table 2

Variance components and genetic parameters for different calf survival traits in the Asturiana de los Valles beef cattle breed

\begin{tabular}{|c|c|c|c|c|c|c|c|c|c|c|c|}
\hline & $\operatorname{Var}(a)$ & $\operatorname{Var}(m)$ & $\operatorname{Cov}(a m)$ & $\operatorname{Var}(c)$ & $\operatorname{Var}(e)$ & $\operatorname{Var}(T)$ & $h^{2}$ & $m^{2}$ & $c^{2}$ & $r_{a m}$ & $\mathrm{Eq}\left(m^{2}\right)$ \\
\hline \multicolumn{12}{|l|}{$P S$} \\
\hline Model 1 & 3124.4 & & & 917.8 & 41373.1 & 45415.4 & 0.069 & & 0.020 & & 0.016 \\
\hline Model 2 & & 1507.5 & & 355.0 & 43224.6 & 45087.1 & & 0.033 & 0.008 & & \\
\hline Model 3 & 3819.3 & 1549.7 & -1379.7 & 507.0 & 40980.5 & 45476.8 & 0.084 & 0.034 & 0.011 & -0.567 & \\
\hline \multicolumn{12}{|l|}{$L M$} \\
\hline Model 1 & 2073.1 & & & 343.4 & 34219.9 & 36636.4 & 0.057 & & 0.009 & & -0.004 \\
\hline Model 2 & & 383.3 & & 3770.3 & 32280.8 & 36434.5 & & 0.011 & 0.103 & & \\
\hline Model 3 & 4149.1 & 1841.5 & -2764.1 & 651.1 & 33060.2 & 36937.8 & 0.112 & 0.050 & 0.018 & -1.000 & \\
\hline \multicolumn{12}{|l|}{ WS } \\
\hline Model 1 & 8071.1 & & & 119000 & 67119.4 & 76380.5 & 0.106 & & 0.016 & & 0.012 \\
\hline Model 2 & & 2906.9 & & 2018.7 & 70559.1 & 75484.7 & & 0.039 & 0.027 & & \\
\hline Model 3 & 10857.5 & 2382.5 & -3547.5 & 1450.0 & 65560.2 & 76702.7 & 0.142 & 0.031 & 0.019 & -0.697 & \\
\hline
\end{tabular}


The results from Model 3 were consistent with those obtained from Model 1 and Model 2 . Heritabilities for the direct genetic effect estimated via Model 3 were always higher than those obtained employing Model 1. Estimations of the maternal genetic effect obtained using Model 3 are more than 2-fold higher than the calculated $\operatorname{Eq}\left(\mathrm{m}^{2}\right)$ and quite similar to the genetic effect estimated by means of Model 2, which is expected to include all the maternal genetic effect and half of the direct genetic effect due to the calf. The permanent environmental effect estimated via Model 3 presents similar values to those obtained using Models 1 and 2. Genetic correlations between direct and maternal genetic effects are both strong and negative, ranging from -0.567 to -0.697 for PS and WS. LM presents $r_{u m}$ outside the parametric space $(-1.000)$.

Model 4 was used to ascertain the genetic relationships between PS and the other traits. Estimated heritabilities for both direct and maternal genetic effects were lower than those obtained by means of Model 3 for the three analysed traits. Heritabilities of the direct genetic effect for PS and LM were around 0.05 , while those obtained for WS was higher (0.083). The highest estimations of the heritability of the maternal genetic effect were obtained for PS (0.023-0.024), being lower for WS (0.016) and zero for LM. PS and WS present high genetic correlations between the respective direct or maternal genetic effects of 0.95 and 1.0. PS and LM shows a high, positive genetic correlation for the corresponding direct genetic effects of 0.745 .

\section{Discussion}

The genetic variability found for calf survival traits would justify the inclusion of some of these in the beef cattle breeding objective. The Asturiana de los Valles breed presents high genetic variability for most of the productive and reproductive traits we have analysed (Gutiérrez et al., 1997, 2002; Goyache and Gutiérrez, 2001; Goyache et al., 2002). The current estimates of heritability for the direct effect of the analysed traits are in agreement with those observed in the literature, while those for the maternal genetic effect are substantially lower. However, most estimates for calf survival refer to perinatal survival or stillbirth in dairy cattle. Koots et al. (1994a), reviewing the literature, calculated a mean heritability of the direct effect of perinatal mortality in beef cattle, of 0.11 and 0.16 for multiparous cows and heifers, respectively. These values were 0.13 and 0.12 for the maternal genetic effect. These average heritabilities were calculated weighting published estimations by the inverse of their sampling variance and transforming the estimations of heritability of dichotomous traits, such as perinatal mortality, to approximate those on the underlying normal scale when they were measured on the observed scale. Koots et al. (1994a) also reported that mean heritabilities of perinatal mortality in beef cattle are, in general, 2-fold or more greater than those calculated in dairy cattle. Meijering (1984), with respect to stillbirth, reported similar heritabilities for the direct genetic effect to those obtained in the current analysis for PS when these were estimated on the underlying continuous scale, but substantially lower values when they were estimated on the observable categorical scale. For Meijering (1984), the maternal component would always tend to be lower than the direct component. There are virtually no estimations of genetic parameters affecting calf survival from the perinatal period to weaning and from birth to weaning. However, Cundiff et al. (1986), using a multibreed population, estimated a heritability for the direct effect of survival from birth to weaning of 0.07 within sire breeds and of 0.11 for the total population.

In our study the heritabilities estimated by means of Model 1 and Model 3 for the direct genetic effect are higher for WS than for PS. However, since our estimates have been done on the observable scale this could be a result of the higher incidence level of WS. To test this we approximated the heritabilities on the underlying normal scale by the equation proposed by Dempster and Lerner (1950): $h_{\mathrm{n}}^{2}=$ $h^{2}(1-p) p / z^{2}$, where $h_{\mathrm{n}}^{2}$ is the heritability on the underlying normal scale, $h^{2}$ is the heritability in the observable binomial scale, $p$ is the population frequency for the trait, and $z$ is the normal ordinate for $p$. After this transformation the heritabilities estimated for the direct genetic effect of both traits become moderate but higher for WS (0.46 using Model 3 and 0.34 using Model 1) than for PS (0.38 using Model 3 and 0.32 using Model 1). This would 
suggest that the higher heritability estimated for the direct genetic effect of WS is a consequence of the higher genetic variability of the trait.

The maternal genetic influence on calf survival traits, if existent, seems to be very low. It is not clear whether maternal genes affect LM. It may be assumed that maternal genetic effects do not influence LM. The value of $\mathrm{m}^{2}=0.050$ obtained for LM by means of Model 3 can be seen as a model artefact provoked by a genetic correlation between direct and maternal genetic effects outside the parametric space. $\mathrm{Eq}\left(m^{2}\right)$ is an intuitive way to ascertain the existence of a maternal genetic component affecting a given trait. However, $\operatorname{Eq}\left(\mathrm{m}^{2}\right)$ is a biased estimation of $\mathrm{m}^{2}$, since the possible existence of covariance between direct and maternal genetic effects is not taken into account. In this sense, the results obtained from a complete model like Model 3 may be more informative.

The sign and size of the genetic correlations between direct and maternal genetic effects affecting calf survival are not fully established in the literature. Meijering (1984) summarised that the genetic correlation between direct and maternal genetic effects (estimated as the maternal grandsire effect) for stillbirth tends to be negative; though it varies greatly in size from moderate to low. Cubas et al. (1989), in Angus cattle under a sire maternal grandsire model, reported a maternal heritability for survival after $24 \mathrm{~h}$ of life of $0.09,2$-fold greater than direct heritability, with a direct-maternal genetic correlation of -0.85 . However, Koots et al. (1994b) reported a low, positive genetic correlation between direct and maternal genetic effects for perinatal survival in heifers and multiparous cows. In dairy cattle, Meyer et al. (2001) found a positive genetic correlation between sire and maternal grandsire genetic effects for perinatal survival of 0.31 .

Even though most analysed survival traits may be affected by a small maternal genetic effect, it is not easy to determine the 'true' genetic influence of the dam on these variables. A possible explanation of the differences found between the current analysis and the estimations of the maternal genetic effect obtained from the literature may be that most published estimations have been obtained employing sire or sire-maternal grandsire models (Meijering, 1984; Meyer et al., 2001). The current estimations were obtained under an animal model. The animal model takes account of every animal's relationships till the base population, leading to a better estimation of genetic additive variances. However, the results obtained from Model 3 may be affected by other considerations. There is general agreement with respect to the deficiencies of the models involving maternal genetic effects. Values of $r_{u m}$ estimated for PS and WS induce one to think that covariance between the two genetic components for these traits is not negligible. In these conditions, the genetic effects estimated under an animal model, especially the maternal component, are forced to be higher by the action of inflated negative correlation between both direct and maternal effects (Gutiérrez et al., 1997; Meyer, 1997). As highlighted for preweaning growth traits, the estimations of direct and maternal genetic effects tends to be imprecise, due to large sampling correlations between parameters (Meyer, 1997). These higher direct and maternal correlations may be partially caused by unaccounted for sources of variation, as a result of differences in management inflating the covariances between paternal sibs in a contemporary group (Meyer, 1997; Berweger Baschnagel et al., 1999) or deficiencies in animal identification (Lee and Pollack, 1997). In preweaning growth traits, a substantial reduction of the directmaternal genetic covariance has been found when additional random effects, such as the interaction between the sire and the comparison group, are included in the model (Robinson, 1996a,b; Berweger Baschnagel et al., 1999), which lead one to consider confusion between environmental and genetic effects resulting in an overestimation of the additive genetic variance and, as a consequence of large sampling errors, biases in the other (co)variance components. It is not easy to think of preferential treatments affecting calf survival traits performance. However, the existence of some unaccounted for environmental factors affecting the estimations of the genetic parameters obtained in the present study by means of Model 3 cannot be rejected a priori. To test this possibility, we analysed our traits by fitting a model including both direct and maternal genetic effects, the covariance between them and the sire as a random permanent environmental effect $\left(s^{2}\right)$ independent on the additive relationship matrix. Since we assume that management practices cannot be different within comparison groups for survival traits, the inclusion of $s^{2}$ in our model should take into account 
Table 3

Parameters resulting from the analysis of preweaning survival (PS) together with each other calf survival traits in the Asturiana de los Valles beef cattle breed by means of a bivariate model

\begin{tabular}{lllllllr}
\hline Analysis & $r_{\mathrm{p}}$ & $h^{2} \mathrm{PS}$ & $h^{2}$ other & $r_{u u}$ & $m^{2}$ PS & $m^{2}$ other & $r_{m m}$ \\
\hline PS-LM & -0.115 & 0.049 & 0.055 & 0.745 & 0.024 & 0.000 & -0.164 \\
PS-WS & 0.732 & 0.043 & 0.083 & 0.948 & 0.023 & 0.016 & 1.000 \\
\hline
\end{tabular}

The table shows the phenotypic correlation $\left(r_{\mathrm{p}}\right)$ between both analysed traits, the heritability for the direct genetic effect for PS and the other traits (LM and WS, respectively), the corresponding heritability for the maternal genetic effect and the genetic correlations between direct $\left(r_{u u}\right)$ and maternal $\left(r_{m m}\right)$ genetic effects.

a possible unadjusted influence of selective matings. Farmers could plan to use some sires only on a given type of dam (i.e., heifers), thus affecting calf survival performance. Estimations of $s^{2}$ were zero for the three survival traits. Although the likelihood of the models including $s^{2}$ was slightly higher than that obtained with models that did not include this random effect (data not shown), the estimates of genetic parameters were not substantially affected by the new effect and are comparable with those obtained by means of Model 3.

Normally, breeders interested in the improvement of calf survival rates have been recommended to use a correlated response to direct selection for calving ease (Cubas et al., 1989). This seemed to be a more feasible alternative in view of the low heritability of perinatal survival and its high, positive genetic correlation with calving ease (Philipsson, 1976c; Meijering, 1984; Cubas et al., 1989). An important topic arising from our study is that the genetic basis (both for direct and maternal effects) affecting preweaning calf survival traits seems to be the same regardless of the moment at which we record calf losses. This is especially true for calf losses occurring in the perinatal period and those recorded at weaning (Table 3 ). The genetic variability estimated for the ability of a calf to be alive at weaning in the present analysis is higher than that estimated for PS. Since the economically important age in production systems based on suckling cows is weaning, this would justify the use of WS instead of PS in beef cattle improvement programs and the estimation of breeding values for this trait (Cundiff et al., 1986). Furthermore, our study supports the hypothesis that the genetic basis affecting calf losses between the perinatal period and weaning is substantially the same as in the perinatal period.

\section{Conclusions}

Current analyses show that selection to improve calf survival rates at weaning would lead to an improvement in calf viability at all earlier ages. Since the first economically important period in suckling cow production systems is the weaning time, sire evaluation for calf survival at weaning would be an interesting undertaking in beef cattle. Additionally, our study shows that the maternal genetic component affecting calf survival can be half or less than half the direct genetic component in size. The estimation of breeding values to select sires to improve the maternal ability for calf survival would not be justified.

Furthermore, since similar results may be obtained for survival traits at weaning using all the recorded information (perinatal losses, losses occurred before weaning and calf alive at weaning) or simplified recorded information (dead or alive at weaning), performance recording could hence be simplified. Nonetheless, the estimation of the genetic correlations between WS and, on the one hand, 'perinatal complex' traits and, on the other, preweaning growth traits should be carried out to build an appropriate selection index for suckling cow production systems.

\section{Acknowledgements}

This paper was partially funded by a grant from CICYT-FEDER, No. 1FD97-1633, and the Principado de Asturias Regional Government through the Consejería de Medio Rural y Pesca. The authors would like to thank the staff of SERIDA-CENSYRA and especially to Teresa Geijo for her kind support and the edition of our database. 


\section{References}

Altarriba, J.L., Varona, L.A., García-Cortés, A., Moreno, C., 1998. Bayesian inference of variance components for litter size in Rasa Aragonesa sheep. J. Anim. Sci. 76, 23-28.

Beef Improvement Federation, 1986. BIF Guidelines for uniform beef improvement programs (5th edition). North Carolina State University, Raleigh, NC, USA.

Berweger Baschnagel, M., Moll, J., Kunzi, M., 1999. Comparison of models to estimate maternal effects for weaning weight of Swiss Angus cattle fitting a sire $\times$ herd interaction as an additional random effect. Livest. Prod. Sci. 60, 203-208.

Cubas, A.C., Berger, P.J., Healey, M.H., 1989. Genetic parameters for calving ease and survival at birth in Angus field data. J. Anim. Sci. 69, 3952-3958.

Cundiff, L.V., MacNeil, M.D., Gregory, K.E., Koch, R.M., 1986. Between and within-breed genetic analysis of calving traits and survival to weaning in beef cattle. J. Anim. Sci. 63, 27-33.

Dempster, E.R., Lerner, I.M., 1950. Heritability of threshold characters (with an Appendix by Alan Robertson). Genetics 35, 212-236.

Goyache, F., Gutiérrez, J.P., 2001. Heritability of reproductive traits in Asturiana de los Valles beef cattle breed. Arch. Anim. Bred. 44, 489-496.

Goyache, F., Royo, L.J., Alvarez, I., Gutiérrez, J.P., 2002. Testing a continuous variation in preweaning expression of muscular hypertrophy in beef cattle using field data. Arch. Anim. Bred. $45,139-150$.

Gutiérrez, J.P., Goyache, F., 2002. Estimation of genetic parameters of type traits in beef cattle. J. Anim. Bred. Genet. 119, 93-100.

Gutiérrez, J.P., Cañón, J., Goyache, F., 1997. Estimation of direct and maternal genetic parameters for preweaning traits in the Asturiana de los Valles beef cattle breed trough animal and sire models. J. Anim. Breed. Genet. 114, 261-266.

Gutiérrez, J.P., Alvarez, I., Fernández, I., Royo, L.J., Díez, J., Goyache, F., 2002. Genetic relationships between calving date, calving interval, age at first calving and type traits in beef cattle. Livest. Prod. Sci. 78, 215-222.

Koots, K.R., Gibson, J.P., Smith, C., Wilton, J.W., 1994a. Analyses of published genetic parameter estimates for beef production traits. 1. Heritability. Anim. Breed. Abstr. 62, 309-338.

Koots, K.R., Gibson, J.P., Smith, C., Wilton, J.W., 1994b. Analyses of published genetic parameter estimates for beef production traits. 2. Phenotypic and genetic correlations. Anim. Breed. Abstr. 62, 825-853.

Lee, C., Pollack, E.J., 1997. Influence of sire misidentification on sire $\mathrm{X}$ year interaction variance and direct-maternal genetic covariance for weaning weight in beef cattle. J. Anim. Sci. 75, 2858-2863.

Matos, C.A.P., Thomas, D.L., Gianola, D., Pérez-Enciso, M., Young, L.D., 1997. Genetic analysis of discrete reproductive traits in sheep using linear and non-linear models: II. Goodness of fit and predictive ability. J. Anim. Sci. 75, 88-94.

Meijering, A., 1984. Dystocia and stillbirth in cattle. A review of causes, relations and implications. Livest. Prod. Sci. 11, 143177.
Meyer, K., 1989. Restricted maximum likelihood to estimate variance components for animal models with several random effects using a derivative-free algorithm. Genet. Sel. Evol. 21, 317-340.

Meyer, K., 1997. Estimates of genetic parameters for weaning weight of beef cattle accounting for direct-maternal environmental covariances. Livest. Prod. Sci. 52, 187-199.

Meyer, C.L., Berger, P.J., Koehler, K.J., 2000. Interactions among factors affecting stillbirths in Holstein cattle in the United States. J. Dairy Sci. 83, 2657-2663.

Meyer, C.L., Berger, P.J., Thompson, J.R., Sattler, C.J., 2001. Genetic evaluations of Holstein sires and maternal grand sires in the United States for perinatal survival. J. Dairy Sci. 84, 1246-1254.

Newman, S., Morris, C.A., Baker, R.L., Nicoll, G.B., 1992. Genetic improvement of beef cattle in New Zealand: breeding objectives. Livest. Prod. Sci. 32, 111-130.

Phocas, F., Bloch, C., Chapelle, P., Bécherel, F., Renand, G., Menissier, F., 1998. Developing a breeding objective for a French purebred beef cattle selection program. Livest. Prod. Sci. 57, 49-65.

Philipsson, J., 1976a. Studies on calving difficulty, stillbirth and associated factors in Swedish cattle breeds. I. General introduction and breed averages. Acta Agric. Scand. 26, 151-164.

Philipsson, J., 1976b. Studies on calving difficulty, stillbirth and associated factors in Swedish cattle breeds. II. Effects of non-genetic factors. Acta Agric. Scand. 26, 165-174.

Philipsson, J., 1976c. Studies on calving difficulty, stillbirth and associated factors in Swedish cattle breeds. III. Genetic parameters. Acta Agric. Scand. 26, 211-220.

Philipsson, J., 1976e. Studies on calving difficulty, stillbirth and associated factors in Swedish cattle breeds. V. Effects of calving performance and stillbirth in Swedish Friesian heifers on productivity in the subsequent lactation. Acta Agric. Scand. 26, 230-234.

Ray, D.E., Itulys, S.B., Roubicek, C.B., Benson, C.R., 1989. Pregnacy rate, calf mortality and calving date in unsupplemented Hereford range cows. Livest. Prod. Sci. 23, 305315.

Robinson, D.L., 1996a. Estimation and interpretation of direct and maternal genetic parameters for weights of Australian Angus cattle. Livest. Prod. Sci. 45, 1-11.

Robinson, D.L., 1996b. Models which might explain negative correlations between direct and maternal genetic effects. Livest. Prod. Sci. 45, 111-122.

Weller, J.I., Gianola, D., 1989. Models for genetic analysis of dystocia and calf mortality. J. Dairy Sci. 72, 2633-2643.

Weller, J.I., Misztal, I., Gianola, D., 1988. Genetic analysis of dystocia and calf mortality in Israeli-Holsteins by threshold and linear models. J. Dairy Sci. 71, 2491-2501.

Wittum, T.E., Salman, M.D., Odde, K.G., Mortimer, R.G., King, M.E., 1993. Causes and cost of calf mortality in Colorado beef herds participating in the National Animal Health Monitoring system. J. Am. Vet. Med. Assoc. 203, 232-236. 